\title{
Negative Experiences in Television Programming : A View from the Other Side
}

\section{Thomas, Suzie}

2017-02-15

Thomas , S 2017 , ' Negative Experiences in Television Programming : A View from the Other Side ' , Archaeologies , vol. 12 , no. 3 , pp. 243-263 . https://doi.org/10.1007/s11759-017-9300-3

http://hdl.handle.net/10138/299815

https://doi.org/10.1007/s11759-017-9300-3

acceptedVersion

Downloaded from Helda, University of Helsinki institutional repository.

This is an electronic reprint of the original article.

This reprint may differ from the original in pagination and typographic detail.

Please cite the original version. 
Negative Experiences in Television Programming: A View from the Other Side

Suzie Thomas,

Published in Archaeologies 12(3): 243-263 (2016).

ABSTRACT: Many professional archaeologists will engage with television. There seems to be little guidance-other than trial and error and personal communications-for navigating interactions with media production companies. Here, through a series of informal questions and answers, I present some issues with which one might be confronted in such engagements. I base my discussions on personal experience, literature and conversations with experienced colleagues. A key point is that media production companies' agendas and priorities often differ from those of archaeologists. While the article draws on experiences from Europe and North America, it has relevance for archaeologists working with television everywhere.

KEY WORDS: Media, Ethics, Television programming, Archaeology

\section{Introduction}

There is every possibility that if you are working as an archaeologist (or in an archaeology-related profession), whether for a government agency, university, charity, private company or as a freelancer, a representative of what might broadly be described as the 'media industry' may approach you at some point. Such representatives may be people from media production companies looking to develop television, radio, and, increasingly, Internet channel programming. For many of us, this might only happen a few times in our careers, and for all of us that get approached, there is a first time. Often, that 'first time' is because a producer or researcher wants particular information and may have spotted your name in a publication, on the Internet or because you have been recommended by a colleague. It was owing to my interest in issues around archaeology and metal detecting, that I was recommended in 2013 as a contact to ClearStory Productions, in what was my first (and so far last) encounter with television programme production. Many archaeologists now know ClearStory as the producers of the infamous 'Nazi War Diggers', originally commissioned and then cancelled by the National Geographic Channel in 2014 after strong opposition from the international archaeological community and others. The programme was later renamed 'Battlefield Recovery' and screened in Poland and the UK in 2015 and 2016. Many in the heritage sector consider the programme objectionable on both scientific and ethical grounds, and in both 2014 and 2016 the programme attracted significant attention on social media. Among other things, critics questioned the appropriateness of handling human remains on camera (Hardy 2016; Brockman 2016a, 2016b), as well as potentially very serious health and safety risks posed by the possibility of encountering unexploded ordnance (Brockman 2016a, 2016b).

I have written elsewhere about my horrified reaction to the programme when its marketing first appeared, the ethical challenges concerning my role as a pre-production consultee, and the proliferation of all kinds of 'experts' vying for the media's attention (Thomas 2015a). It is not my intention to revisit that discussion fully again here. However, the experience itself and the process of writing the article and taking part in debate afterwards (see Moshenska 2015; Ewen 2015; Flatman 2015; Holtorf 2015; Thomas 2015b) led me to talk about the issues around media engagement with various colleagues. These colleagues work in the USA, where in recent times attempts have made been to work more closely with broadcasting networks to try and improve 'archaeologically problematic' programming, in my native UK, and in my current country of 
residence Finland, where there seems to be a recent increase in proposals for television shows featuring metal detectorists.

While participating in these discussions, it struck me that despite recurring instances in the literature of archaeologists discussing their relationship with the media (for example Clack and Brittain 2007; Fagan and Rose 2003; The SAA Archaeological Record 2015), there is still very little practical advice for individual archaeologists being approached by production companies (notwithstanding such as DeCicco 1988focusing more on how archaeologists can develop their own public relations rather than on consultative roles). Too often, it is left to personal judgement concerning whether to agree to consult or otherwise advise, let alone participate in a programme designed for broadcast, a decision made more difficult in cases where one has only limited or no previous experience of such encounters, or is working in an environment where peer advice may not be forthcoming or available.

We are also often told, through various codes of professional standards, as well as through an increasing collective awareness within our discipline about the importance of public engagement and education, that we have a duty to engage with the wider public. Should this engagement not include offering advice when asked by those in society who have a real possibility to influence many people, such as television programme makers? Even 'open' forms of communication such as blogs, Facebook and Twitter, arguably reach only a small fraction of people compared to television programming (Altschul 2015, 4).

After careful consideration and inspired by a suggestion from a close, trusted colleague, it seemed timely, and perhaps on a personal level for me, important, to write this article, intended for early career archaeologists and other colleagues who may be facing difficult decisions regarding media production company interactions. In the following sections, I diverge from what might be considered a 'typical' format for academic writing and frame my perspectives - from my own experiences but also from discussions with peers - in the form largely of questions and answers. Some of these answers are, inevitably, framed around my personal understanding and are often reflexive in tone. Many suggestions and observations are more general, and also reflect the experiences of others with whom I have spoken, and who have offered comments and insights that I have worked into this piece (see also the Acknowledgements). In this way, I hope to address at least some of the possible issues that may help people in a similar position to the one in which I found myself.

This discussion includes points to consider before deciding whether to work with a production company, but also addresses some of the anxiety you might experience, should the outcome not correlate with your expectations. We should always remember that the objectives and goals of media production companies are almost certainly going to be different to those of archaeologists and heritage professionals. This point is not to suggest that media production companies intentionally sabotage an archaeologist's 'good intentions', but it is important to remember that your own expectations of what makes a successful media output may be at variance with those of the production company personnel. You can never fully predict exactly when a bad, even damaging, outcome from a correspondence or collaboration will occur. However, you can (and should!) learn from your own experiences and the experiences of others.

\section{Things to Consider Before Agreeing to Consult, Give Advice or Otherwise Participate in a Media Project}

The first stage in any interaction is the initial contact-usually by email or occasionally by telephone or via social media. The production team with whom I spoke were very courteous, enthusiastic and (of course) very complimentary about me and my research. I was also flattered that a colleague, someone I knew and respected, had thought of recommending me to them. It was exciting to be asked to do something like this. Because they proposed to work with metal detectorists, and that was an area where I have undertaken 
specific research, it felt like an opportunity to make a positive impact, giving advice on one of my areas of knowledge. It also seemed to me from our conversations that the company really was trying to approach their chosen subject in a responsible way by contacting not only me, but other archaeologists too.

Talking to a production company, and asking for further information, does not mean that you have actually advised them, nor does it obligate you to give them advice. Just because you have offered information and advice at this or any point also does not mean they are obligated to take that advice. A company could also use the fact that they have spoken to you to encourage others to work with them. With these considerations in mind, here are some questions to consider, and areas to try to obtain more information about, before making a decision whether or not to follow up on an initial approach from the media.

\section{What is the Project Really About?}

Sometimes your contact may be vague about what they are planning. This could be because they are still at an early stage of the process, and are not yet sure of the direction that it will take. Cynics could speculate that they may also sometimes try to phrase their ideas in a way that sounds less controversial than it is, if they suspect that what they want to do might not gain approval from professional archaeologists (connected to this: as non-specialists they may not realize that there are ethical or other types of problems connected with what they want to do).

\section{How Much More Can I Find Out?}

The moment someone approaches you, start to take notes, including the date, time and who you are talking to. Ask many questions and ask to see information that they have. Make sure you have the name of the production company who you are talking to. Press for more information if they only tell you that they are making a programme for a particular broadcasting network (such as Channel 4, National Geographic Channel or who-ever). The network is just the distributor's publisher, whereas the production company themselves are the ones making the programme. End the first telephone conversation with a request for them to email you with a précis of what you have been talking about. Obtaining information in writing (rather than verbal) will also give you time to revisit and study the information more carefully, and give you a record of what they have said.

Look up the production company's previous work: their websites often have trailers and show reels so that you can see what their work is like. If you email them questions that are repeatedly ignored, this should cause you concern. If you are meeting any of the company's representatives in person, ask them to come to you. If that is not possible, apply the normal rules of personal safety. Meet in a public place, and tell someone where you are going, who you are meeting and when you expect to be back. You could also take someone along with you. As one colleague said to me, 'two sets of eyes are always better than one'. Finally consider investing in a digital voice recorder or smartphone sound recording app. You can ask if your contact minds if you record the meeting for personal use as notes. A legitimate contact will not mind this, and reporters do it all the time, so asking to record a meeting as an aide memoire simply looks professional.

The company may or may not be willing to share information such as programme treatment (the first stage in outlining a programme idea) let alone a draft shooting script with you. Bear in mind too that depending on the stage, this information may not yet be available. The company may also have confidentiality reasons for not wanting to give you too much information at this stage, but you can ask about seeing it anyway. It is also worth finding out, if possible, about who they have on their own research team. One colleague I spoke to felt reassured by the fact that a production company they had engaged with had a qualified archaeologist with relevant specialist knowledge already employed as a researcher. This encouraged them to agree to work with the company themselves. 
If you are told such things as 'we have spoken to other experts already', or 'we had a very positive meeting with [name of organization or individual]', try to find out details-from them but also from the organization or individual that they mention. Just because a meeting or conversation took place, does not automatically mean that the organization or individual was as positive about the project as the production company might suggest.

\section{What Will My Contractual and Financial Relationship be with the Production?}

I remember a professor when I was an undergraduate regularly complaining about the press for asking him for information but offering no financial compensation for his time, nor even citing him as the source of their information. While it may feel indelicate to discuss, time does cost money, and it is both appropriate and professional to talk about it. Make clear under what terms you would continue to talk to the production company. Most people would not charge for an initial meeting. However, if not discussed already, at the end of that initial meeting, you could say something along the lines of, 'obviously if you need anything more specific we would have to discuss how long that would take and what it might cost'.

Most often companies are willing to take you on as an official consultant. With that status comes a contractual agreement and, if you have negotiated properly, a consultancy fee. There are various aspects to consider, especially if you have not yet reached an agreement concerning your relationship with the production company and your employer: Will you do this in your own capacity? Or are you officially representing your organization? What is your employer's policy concerning freelance consultancy? (For example, many universities will allow their staff to work up to a limited amount of time per year in this capacity.) If you do take on consultancy, do you receive the payment yourself, or does your organization receive it? If you receive the money yourself, you need to find out what your tax status is regarding freelance income. Does your employer have guidelines, or even set rates for your consultancy fee? For these particular details, you may need to seek advice from beyond your immediate manager, for example from your finance department, if your employer has one.

If you are in a salaried post, you should always make sure that your employer is aware that you have been approached for consultancy. If you work freelance, or are otherwise in a position to set your own consultancy fee, it is useful to know what current rates are for broadcast researchers, as that will be the figure that companies are most familiar with (for UK, e.g. Televisual 2014). However, few people working in television earn high amounts of money (unless they are at the most senior levels), so you should offer what you think you are worth. You are, after all, offering a specialist service, and you have spent many years gaining your expertise and qualifications. Finally, whatever agreement you have reached, establish what exactly you are being asked to deliver and how much time you are expected to spend delivering it.

\section{Can I Talk About the Programme While It is in Development?}

The company is likely to ask you to sign a non-disclosure agreement (NDA), with the effect of limiting what you can say about the production and when you can say it (often to protect their concept while it is still in development). This condition is potentially problematic, as such agreements can represent a limitation of freedom of speech and academic freedom. One colleague told me how he was involved in a potentially controversial project, and was able to get the NDA eliminated from the archaeological team's contracts. It was replaced with an agreement that the team could publish on any aspect of the work in academic and other publications as long as they were not profiting from the sponsoring company's intellectual property (see Brockman et al. 2015). This contract also carried a public interest clause, allowing the team to speak out if they identified an issue that they deemed was in the public interest to raise. In return, the team agreed not to publish anything until the project was in the public domain without first consulting the company. Not every production company may be willing to do this, and too restrictive a clause concerning 
what can be disclosed might also be a warning signal and an indicator to end your relationship with the project.

\section{What Exactly Do They Want Me to Do?}

The amount of work asked of you, and the extent to which you have the opportunity to influence the process directly, will vary from a telephone brief through desktop work and archive research, to participation on the actual recording, behind, or even in front of, the microphone or camera. In my case, I was presented (in connection with the pilot episode only) with early-stage questions to answer based on my areas of specialism, which I believed would be used to inform further decisions later in the production process. I was also shown an internal briefing document for National Geographic Channel about the goals of the programme, in which I and another archaeologist were named, just before the official National Geographic Channel marketing was released (marketing which I did not see until it was publicly available).

In most cases, your role should be made clear to you, and if it is not make sure to ask for clarification. If your role is relatively small (as mine was), this may be positive in the sense that it will demand less of your time, but it also in turn affects your capacity to influence the end product. In all cases advisors and researchers are exactly that (advisors and researchers)-and we may not have as much influence as we would like, if any, on what finally appears.

\section{Where Can I Get Advice?}

It is worth talking to different people about whether to take on a media consultancy-especially if you are unsure about the nature of the project or are inexperienced in this type of work. If you work at a university you should talk to your legal team about your rights-especially concerning the nature of any contracts or other agreements, and to the university media services about the potential implications-both positive and negative-in terms of public relations. If the project looks in any way prestigious or high profile they will likely want to feature you in their publicity. You should also talk to your line manager. Unfortunately not everybody works with a supportive or even interested boss, or one that has media experience. Therefore, it is important to talk to other people as well. In particular, if you have colleagues who have worked with the media before, you could talk to them about their experiences.

Many professional codes of ethics indicate that public engagement should be encouraged, although they do not (and cannot) counsel for every conceivable scenario. There is also an increasing amount of literature about working with the media, and this can be insightful for both the positive and negative sides of this kind of work, as well as for arguments about whether it is worth the effort at all.

As many have noted (e.g. Corbishley 2011, 53), complete satisfaction with the outcome of media engagements is rare, and archaeologists are frequently frustrated with the final product. Obviously the degree of frustration varies, depending on the quality of the final programme and your own level of practical and emotional engagement with it.

Ultimately though, you will still have to make the decision yourself as to whether to cooperate or not, and you might not agree with all of the advice that you receive. It is not unusual, or a sign you have made a mistake becoming involved in the first place, to feel ambivalent about your involvement in a programme, especially in the period between your involvement and the actual broadcast, when a lot of other people have direct input to the creative process and you have gone back to your day job.

If your input does not prevent an ethically objectionable programme from airing, it is you who has to live with the consequences of that. Similarly, if you had the opportunity to give advice but turned it down, and a poor product resulted, that is also something to reflect upon, although the chances are the product may 
still been bad even if you had been involved.This article's references serve also as a starting point for those wishing to read more on these issues.

\section{Thoughts You Might Have If You are not Happy with the Outcome of Your Involvement}

In an ideal scenario, the collaboration between archaeologists and the media results in the opportunity for the specialist to input into popular culture and reach exponentially more lives than are ever touched by an academic paper. It also allows the producers to present something that is well informed, ethically sound, and that takes into account the latest research and ideas. However, this is not always the case-and as many others have noted, the end product is often not even close to the consultant's expectations.

Academic commentators have criticized many aspects of media engagement, from the time it may take, through to the media's use of titles such as 'researcher' and 'expert' for 'talking heads' with few or no qualifications. Academic historian and experienced television presenter, Eduardo Pagán, disclosed that he is 'especially irked by talking heads who are dubbed as 'historians' when, in fact, they are not credentialed through degrees, have never published in peer-reviewed journal articles or seem to have no understanding of professional research standards' (Pagán 2015, 12). Peebles also notes that many metal detectorists are 'extremely knowledgeable about local, regional, or national history and material culture' (Peebles 2015, 32 ), and it is these and other knowledgeable individuals that production companies may be presented with -in addition to, or even instead of, archaeologists. We also know from community archaeology research and from critical heritage studies that there are countless different perspectives, kinds of knowledge and priorities other than those of archaeologists when it comes to how cultural heritage is treated and used.

Furthermore, personality is important on television. In an interview, National Geographic Society representative John Francis revealed the initial motivation of the National Geographic Channel to agree to commission the American metal detecting reality show 'Diggers':

As with many programs, an external production company presented a series concept, which was commissioned and in the course of actual production further evolved. The idea of following two charismatic metal detectorists, King George (or KG) Wyant and Tim 'The Ringmaster' Saylor (or Ringy), on surveys of historically rich land was deemed an appealing topic that would celebrate history and heritage and highlight the excitement of related discoveries. (Herr 2015, 19)

Words such as 'charismatic', 'appealing' and 'excitement' jump out from this quotation, and shed further light on the motivations of programme commissioners. Worst-case scenarios may result in highly problematic programming, ultimately driven more by what producers believe to be 'good television' (i.e. television shows that will attract viewers) than scientific or ethical considerations. The reality is that the producer's quest for what they consider 'good television' may trump our notions, as heritage professionals, of ethics and science.

Is this focus on personality and 'excitement' over scientific substance a problem? Sometimes, although it is also a reminder that the goals of television and other media have very different drivers to those of academics and other professional archaeologists. The entertainment industry is driven by market forces, and what is broadcast is ultimately an outcome of those demands. 'If a show on squirrels eating nuts pulled in over a million viewers, there would be more shows on cable television of squirrels eating nuts' (Pagán $2015,13)$. 
Nonetheless, if you do find yourself at the uncomfortable end of an unpleasant experience with the media - which may have failed to meet your expectations or, worse, displayed archaeologically unacceptable behaviour on camera-you may find that you are asking yourself all manner of questions about your role, and whether you could have done anything differently. Questions going through your head may include the following.

\section{Was the Advice I Gave Clear Enough?}

Maybe it was, maybe not. There are bigger issues here about human communication and about how we might or might not be able to ensure that our message is not only received, but also understood. Styles in communication can vary from culture to culture and from person to person. Even in editing the Journal of Community Archaeology and Heritage, I and my American Co-Editor often quip about our different 'styles' of relaying feedback to potential contributors. It is always possible for points to get 'lost in translation' or for signals to be misread.

I also cannot say often enough that, as far as the media are concerned, archaeologists are not the only show in town. Depending on the topic of the programme, companies may well be consulting others who regard themselves just as much 'expert' as do archaeologists. These can be anyone, from specialists in other disciplines, through to people with fields of knowledge that archaeologists traditionally consider to be ethically dubious (such as the market knowledge held by antiques dealers), through to every 'selfeducated expert' under the sun. This will include metal detectorists, collectors, those that we like to label as 'alternative', 'outsider' or 'pseudo-' archaeologists (see also Wilson 2012), celebrities, psychics and anyone else that media companies-and the public-might consider interesting or entertaining. We must remember that the media responds to (as well as leads) public tastes and whims.

This means that a production team can be confronted with all kinds of 'advice' and 'knowledge' from any range of groups and individuals. In many cases, the production companies, and indeed the wider public, are not equipped to distinguish between reliable information and the downright fanciful. They could also claim, in some cases, that the advice you offered could not be followed for artistic reasons-because it 'wouldn't look good on television'. In the end, too, entertainment wins out, and producers may cut corners in order to make for what they see as more engaging and immediate television. This is entertainment that fits within a limited time slot, presented in a way that producers hope will prevent the viewer from getting bored and switching to another channel. Without taking complete leadership of the production process (impossible without switching careers-although see Pettigrew 2015), we have no control over who else they consult or the extent to which they take heed of our recommendations over those of other 'experts'.

\section{Was I Too Polite?}

This question, related to the previous one, came up in a conversation I had with a colleague who was also in discussions with a production company (unlike me he even met representatives in person) and who would have continued to work with the company, had he not had major concerns with the direction of the programme after viewing a pilot episode. We both wondered whether we had been overly polite in our interactions; in both cases the team members that we engaged with were incredibly affable and friendly, and in such a polite situation it might be difficult to use stronger language. That is to say, pleasantries may have diluted certain messages, or not conveyed the importance of doing or not doing certain things. It is hard to tell with hindsight, of course, whether a firmer approach to communication would have been more fruitful. Similarly it is impossible to turn back the clock to see how a show would have turned out, had you not offered any advice at all.

Could I Have Ensured that Other Specialist Advice, Beyond My Own, was Taken? 
You can recommend other specialists, and this is a very good idea especially in cases where you know that there are people with wider knowledge or experience than you of certain aspects that the production company wishes to explore. However, you must start from the point that in practice you have little, if any, control over: (a) whether the company takes your advice and contacts these other specialists; (b) whether the specialists in question will agree to give advice; or (c) whether the company will heed their advice, especially if it expresses doubts as to the wisdom of their plans.

These other specialists may be individuals who are more sceptical than you about these sorts of engagements - they may see problems that you did not see, or may be put off media consultation owing to past negative experiences. You may be tempted to be insistent-for example refusing to consult unless ' $D r$ $X^{\prime}$ ' or 'Prof. $Y$ ' also agrees to consult, but whether this is actually practicable is debatable. You possibly don't want to be in the position of appearing to coerce others into 'coming on board' with you, especially if they have their doubts.

I would again reiterate-based on conversations with others - that companies may sometimes not be entirely clear with you about how communications with other specialists have gone. Their version of a meeting might be that 'we had a great conversation with $\operatorname{Dr} X$, and she was very helpful and informative', whereas $\operatorname{Dr} X^{\prime}$ 's interpretation of the same meeting might be 'I met them, and I told them it was a terrible idea and that I want nothing to do with it'. This is not to suggest that companies are always deliberately misleading about their encounters with other specialists. Nevertheless, if you do know (or know of) the individuals with whom they say they have spoken, contact them to hear their side of the story.

\section{Is It My Fault that the Programme Looks the Way It Does?}

The final appearance and content of a programme on which you were consulted is the result of a lot of things. Yes, your advice will have affected it somehow, even if only in small ways, but so will a lot of other influences and factors. You may find yourself feeling angry, deceived or used. Was your involvement simply a tool for the company to 'legitimize' their show? In darker moments, you might start to question your own judgement, and your ability to give sound advice. You may also feel ashamed. One fact is clear though, a fact that you should never forget: you did not produce the programme. The production company did.

After the late Professor Mick Aston left Time Team, the iconic archaeology programme that he had cocreated, he said that he regretted that he had not hired an agent to handle negotiations with the production company and the network. He also regretted that he had not taken on an Associate Producer role, which would have put him in a seat around the decision-making table with the commissioner, Channel 4 (Current Archaeology 2013). While most of us will never operate at the levels of televisual engagement that Aston did, it is instructive to learn that even he experienced difficulties with the production process.

\section{Is My Reputation, or Even My Career, in Jeopardy Over This?}

Descending from the ivory tower to engage with the wider public, especially media, is always daunting, and especially in this digital age it is increasingly difficult to distance oneself from unsuccessful collaborations. I can honestly say that I have lost more sleep worrying about the repercussions to my career due to this one experience, than about any other single thing that has happened in my professional life. I've said to more than one acquaintance, 'what I wouldn't give for a time machine!' However, it did all happen-I consulted for the production company, and the programme that they finally produced was (in my view, and that of many colleagues) shockingly, disastrously, horrifyingly, awful. There is nothing I can do about that truth. Time will tell whether my reputation is seriously damaged by the experience, although I have been fortunate in receiving messages of support and solidarity from colleagues whom I trust and admire. Many more have pointed out that colleagues are usually very sympathetic in these situations, especially if they have had 'bad media experiences' themselves. I daresay that others might have a far more critical 
viewpoint on my involvement. Metal detectorists, many of whom have been vocal in criticizing the programme and the way it depicts metal detecting, may also be disappointed to learn of my connection, given my efforts to present their hobby's history and their viewpoints in my other work.

However, in a situation such as this, it is important to keep perspective and to remember that, to the outside world, you and your career are not the most important or even the most interesting aspects of the larger story playing out. As recognition of my input, the company told me that my name would appear in acknowledgements in the end credits of one episode. At the time, this sounded fair-it is only right to acknowledge the input of others. Once the programme was announced, and its title and nature publicly known, I was sickened at the thought of my name being associated with the show at all. I even requested that my name be removed and offered to return my consultancy fee (of $f 200$ ), but this appeared not to be possible. It has since been suggested to me that this sort of editing should have been possible, right up to when the programme was transmitted, and that I should have been firmer in my request for my name to be taken down. With hindsight, it would have been wise to insist as part of my written agreement that my name appear only if I approved of the end product-sometimes referred to as an 'Alan Smithee' clause. This name derives from the practice of Hollywood film directors to insist their name be removed from end credits in instances when they are dissatisfied with the final edit, replacing their own name with the shared pseudonym of Alan Smithee (Decherney 2011). Hence, it has been adopted as a nickname for an option in a contract to withhold one's real name in the event that one is unhappy with the final production (Alan Smithee is also an anagram of 'the alias men'). On the other hand, it is disingenuous to disassociate entirely from the experience, which is why I wrote my article in 2015 , and why I have written this current piece.

Working in academia, I already know that you cannot please everyone all the time. It is the nature of scholarly discourse to challenge assertions by others, and in turn to see your own ideas and research challenged, even thoroughly dismissed. As a researcher of the metal detecting community, I have already had my fair share of negative reaction from commentators who do not see the value of trying to understand the worldviews and activities of this controversial group in anything deeper than assumptionbased polemics. Criticism, but also praise and encouragement, has come to me since my days as a doctoral student-my Ph.D. supervisor once even advised me to 'get over' being upset about negative comments. And so I-like so many scholars in all kinds of situations-have learned to develop a thick skin. This does not mean that negative comments and criticisms do not hurt, and will not hurt when they appear in the future. It is also a sad irony for me that, although a lot of my research has been dedicated to understanding the relationships between archaeologists and metal detectorists, the portrayal of metal detecting and detectorists in 'Battlefield Recovery' might actually sour relationships between the two groups.

I will end this section of my discussion by quoting Gabriel Moshenska, one of the commentators on my article reflecting on my experiences of consultancy:

...there must be a space, as Thomas has opened in her paper, for media-active archaeologists to reflect thoughtfully and self-critically on their experiences without fear of attack. The discussion is an important one, and I hope it can continue with courtesy and respect.

(Moshenska 2015, 329)

\section{Should I Avoid Such Engagements in the Future?}

My own visceral, instinctive feeling at present is to avoid media engagement at all costs, such was the trauma of my experience. I suspect others reading this may be thinking the same and regarding my tale as a cautionary one. However, would that be the right course of action? Is the instinctive reaction also the most professional reaction? Throughout my research, especially that on metal detecting, I have advocated trying to understand the perspectives of others, and acknowledging that different communities and groups may have different values and perspectives to professional archaeologists (echoing also Smith and Waterton's 
critique of the 'authorized heritage discourse', e.g. Smith and Waterton 2012). Furthermore, it is important to learn from experiences-especially bad ones-and to find ways to 'do it better' in the future.

In the aftermath of learning that 'Battlefield Recovery' was to be broadcast on UK television, archaeologists once again took to Twitter, with some urging 'us', as 'experts', to refuse to give any advice to the offending production companies or broadcasting networks in the future. Would this kind of strategy really end all 'bad archaeology' on television? I have difficulty in seeing how.

Former Society of Historical Archaeology President Charles Ewen has written openly about his experiences engaging with the producers of 'Diggers' to try to improve the content of the show from an archaeological perspective, even in the face of criticism from some quarters. He also notes that archaeologically unethical programmes such as 'American Diggers' - following around a former professional wrestler as he excitedly metal detects for artefacts and attempts to sell them for the highest price he can get-are nonetheless proving popular with viewers.

Surely there is some middle ground that gets our point across without boring the public to tears? We will see if Diggers can strike that balance. It has become apparent that these 'reality' shows are not going away. They are cheap to make and audiences like them. And whereas almost a million viewers watched the last episode of Diggers, more than a million watched the last episode of Spike's travesty, American Diggers. (Ewen 2013)

This is not by way of justifying all engagements with the media no matter what, and my involvement with the pre-production of that programme is likely viewed by many, including myself with the benefit of hindsight, as an ill-informed, even naïve, decision. It is, I would suggest, vital to think very carefully about the possible implications of involvement versus non-involvement, but also to be prepared for the possibility that your good intentions may not prevent negative results. Try to have a 'plan B' ready to go the moment the client's actions, or your own instinct, suggest that all might not end well.

\section{Should I Talk About What Happened?}

Absolutely. It is possible that it will be painful, at least at first, to confront the situation in your mind, and to recollect the interactions and what happened. You may also have the urge to distance yourself as much as possible from the final production-perhaps worrying about how peers and colleagues will react to you when they find out. This feeling is completely understandable, and nobody expects you to offer your head on a block as a sort of 'scholarly sacrifice' due to an unpleasant experience with the media.

On the other hand, if you keep quiet, or worse, deny all involvement, it is likely that your involvement will come to light later somehow (perhaps through colleagues who know you were involved, perhaps from the media company themselves, or because someone sees your name on the end titles because you did not think-or did not know it was possible-to request an 'Alan Smithee' clause in your contract). This may lead to further difficult questions for you, and besides you will expend more stress and energy worrying about being 'discovered' than if you simply 'own' what happened, and share your experiences. It avoids the possibility of appearing disingenuous, especially if you feel that you should speak up in objection to the final product.

For my part, I have been hesitant to engage too heavily in debates on social media such as Twitter, partly due, indeed, to concerns about appearing disingenuous, and partly due to the limited space available in such exchanges to articulate my thoughts and experiences fully. Furthermore, I am aware of how easy it is to respond in haste on social media, something I did not want to do in this situation. Even more importantly, every interaction we have in life offers lessons - to ourselves and to others. Therefore, talking or writing about your experience will be valuable to other colleagues, especially those who have little or no 
experience of engaging with media companies. Let others learn from your experiences, while at the same tome contributing to the ongoing debates about archaeology and the media.

\section{End Point and Hindsight}

Many consider archaeology to be an inherently interesting subject. The Chair of the Society for American Archaeology's Task Force on Metal Detecting of Archaeological Sites on Reality Television, Giovanna Peebles, said that '[w]e are the ultimately cool people in the ultimately cool profession' (Peebles 2015, 30). While 'cool' is in the eye and mind of the beholder, others have suggested similarly that archaeologists are more likely than colleagues in other academic disciplines to 'deal with media and media issues' (Clack and Brittain 2007, back cover). It is also true that media companies', and by extension, the public's perceptions of what archaeology is about may not necessarily mesh exactly with the perceptions held by archaeologists themselves (Holtorf 2007; Paynton 2002). To some extent, we maybe have to accept this aspect of archaeology's role in popular culture, although as others strongly urge, we also have a professional and ethical responsibility to present an accurate portrayal of the work that we do (e.g. Vitelli and ColwellChantaphonh 2006, 9). Against that background the questions above, plus many more that I have perhaps missed, are the kinds that could keep you up at night, but they can also empower you to think about your approach next time a production company contacts you. Be firm, and be absolutely clear about the issues you feel are most important. On a personal level, this could include the use of your name. If a company (or even your employer) suggests it wants to mention you in the media in relation to the programme, or to acknowledge you on end credits, it is worth insisting on an agreement-in writing - that if you do not approve of the final product, you can veto use of your name. Companies may object to this at first, especially as using names of specialists helps them legitimize their programme and appear to show due diligence, but stand your ground. This should include vetting any contractual agreement for terms and conditions; it is worth having such agreements checked with a legal advisor from your institution or union.

If there is anything that you are not sure about, do not agree to it. Of course, hindsight is 20-20, and it can be difficult, especially if you have little experience of media engagement, to foresee any potential problems at the early stages. This is where talking to colleagues, and reading about different experiences, helps to equip you. Trying to do the right thing is difficult, and everybody has a different opinion, based on experience, interests and personal ethics, about what 'right' is. Even if you have good intentions, as I certainly did, this is no guarantee that problems will not arise. If you manage to get through your career without any failures or bad experiences, you are likely extremely fortunate, and a rarity among your colleagues. Learning from them, and sharing your experiences with others, salvages something positive.

\section{Acknowledgements}

I am indebted to Andy Brockman, Jan Fast, Natasha Ferguson, Carol McDavid and Anna Wessman for commenting on drafts of this article and for sharing their own personal insights and experiences with me.

\section{References}

Altschul, J.H. 2015. From the President. The SAA Archaeological Record 15(2): 3-4. Full text:

http://www.saa.org/Portals/0/SAA/Publications/thesaaarchrec/March2015.pdf. Accessed 9 February 2016. 
Brockman, A. 2016a. Rolling News: 'Nazi War Diggers' Gets UK TV Debut on Channel Five as 'Battlefield Recovery'. The Pipeline, blog. http://thepipeline.info/blog/2016/01/05/rolling-newsnazi-war-diggers-getsuk-tv-debut-on-channel-five-as-battlefield-recovery. Accessed 9 February 2016.

2016b. EOD expert confirms 'Battlefield Recovery' Showed 'potentially lethal' Practice. The Pipeline, blog. http://thepipeline.info/blog/2016/01/09/eod-expert-confirmsbattlefield-recovery-showed-potentiallylethal-practices/. Accessed 9 February 2016.

Brockman, A., M. Brown, R. Scott, and T. Speight 2015. Assumed Missing Reported Buried: The search for the lost Spitfires of Burma. F37/34 Publications, London.

Clack, T, and M Brittain (editors) 2007. Archaeology and the Media. Left Coast Press, Walnut Creek. Corbishley, M 2011. Pinning Down the Past: Archaeology, Heritage, and Education Today. The Boydell Press, Woodbridge.

Current Archaeology. 2013. Exclusive Interview-Mick Aston: An Archaeological Journey. Current Archaeology. http://www.archaeology.co.uk/articles/features/exclusive-interview-mick-aston-anarchaeological-journey.htm. Accessed 9 February 2016.

Decherney, P 2011. Auteurism on Trial: Moral Rights and Films on Television. Wisconsin Law Review 2:273330.

DeCicco, G 1988. A Public Relations Primer. American Antiquity 53(4):840-856.

Ewen, C. 2013. National Geographic's Diggers: Is it Better? SHA Blog.

https://sha.org/blog/2013/02/national-geographics-diggers-is-it-better/. Accessed 9 February 2016

2015. Comments. European Journal of Archaeology 18(2):332-333.

Fagan, B, and M Rose 2003. Ethics and the Media. In Ethical Issues in Archaeology, edited by L Zimmerman, KD Vitelly, and J Hollowell-Zimmer, pp. 163-176. Altamira, Walnut Creek.

Flatman, J 2015. Comments. European Journal of Archaeology 18(2):330-331.

Hardy, S. 2016. Nazi War Diggers' Battlefield Recovery: Playing Soldiers and Exhuming them. Conflict Antiquities, blog. https://conflictantiquities.wordpress.com/2016/01/25/poland-nazi-wardiggersbattlefield-recovery-exhumation-ethics. Accessed 9 February 2016.

Herr, S. 2015. Interview with John Francis on National Geographic and Archaeology Programming. The SAA Archaeological Record 15(2): 18-20.

http://www.saa.org/Portals/0/SAA/Publications/thesaaarchrec/March2015.pdf. Accessed 9 February 2016.

Holtorf, C 2007. Archaeology is a Brand!: The Meaning of Archaeology in Contemporary Popular Culture. Archaeopress, Oxford.

2015. Comments. European Journal of Archaeology 18(2):333-334.

Moshenska, G 2015. Comments. European Journal of Archaeology 18(2):328-330.

Pagán, E. 2015. Digging for Ratings Gold: American Digger and the Challenge of Sustainability for Cable TV. The SAA Archaeological Record 15(2): 12-17. http://www.saa.org/Portals/0/SAA/Publications/thesaaarchrec/March2015.pdf. Accessed 9 February 2016.

Paynton, C. 2002. Public Perception and 'Pop Archaeology': A Survey of Current Attitudes Toward Televised Archaeology in Britain. The SAA Archaeological Record 2(2): 33-36. 
http://www.saa.org/portals/0/saa/publications/thesaaarchrec/mar02.pdf\#page=35. Accessed 9 February 2016.

Peebles, G. 2015. Reality Television and Metal Detecting: Let's be Part of the Solution and Not Add to the Problem. The SAA Archaeological Record 15(2): 30-34.

http://www.saa.org/Portals/0/SAA/Publications/thesaaarchrec/March2015.pdf. Accessed 9 February 2016.

Pettigrew, R. 2015. Going Around (or beyond) Major TV: Other Media Options to Reach the Public. The SAA Archaeological Record 15(2): 38-39.

http://www.saa.org/Portals/0/SAA/Publications/thesaaarchrec/March2015.pdf. Accessed 9 February 2016.

Smith, L, and E Waterton 2012. Constrained by Commonsense: The Authorized Heritage Discourse in Contemporary Debates. In The Oxford Handbook of Public Archaeology, edited by R Skeates, C McDavid, and J Carman, pp. 153-171. Oxford University Press, Oxford.

Televisual 2014. Reports and Surveys: Salary Survey. Televisual. http://www.televisual.com/readreportssurveys/26/Salary-Survey-2014.html. Accessed 9 February 2016.

The SAA Archaeological Record 15(2). Themed Issue: Archaeological Practice on Reality Television. http://www.saa.org/Portals/0/SAA/Publications/thesaaarchrec/March2015.pdf. Accessed 9 February 2016.

Thomas, S 2015a. Collaborate, Condemn or Ignore: Responding to Non-archaeological Approaches to Archaeological Heritage. European Journal of Archaeology 18(2):312-328.

2015b. Comments. European Journal of Archaeology 18(2):334-335.

Vitelli, K, and C Colwell-Chantaphonh 2006. Introduction. In Archaeological Ethics, edited by K Vitelli, and C Colwell-Chantaphonh, pp. 1-15. Altamira, New York.

Wilson, J 2012. The Cave Who Never was: Outsider Archaeology and Failed Collaboration in the USA. Public Archaeology 11(2):73-95. 